\title{
Dynamic Behaviors of Growth Cones Extending in the Corpus Callosum of Living Cortical Brain Slices Observed with Video Microscopy
}

\author{
Mary C. Halloran' and Katherine Kalil ${ }^{1,2}$ \\ ${ }^{1}$ Neuroscience Training Program and ${ }^{2}$ Department of Anatomy, University of Wisconsin-Madison, Madison, Wisconsin \\ 53706
}

During development, axons of the mammalian corpus callosum must navigate across the midline to establish connections with corresponding targets in the contralateral cerebral cortex. To gain insight into how growth cones of callosal axons respond to putative guidance cues along this CNS pathway, we have used time-lapse video microscopy to observe dynamic behaviors of individual callosal growth cones extending in living brain slices from neonatal hamster sensorimotor cortex. Crystals of the lipophilic dye 1,1'-dioctadecyl-3,3,3',3'-tetramethylindocarbocyanine perchlorate (Dil) were inserted into the cortex in vivo to label small populations of callosal axons and their growth cones. Subsequently, $400 \mu \mathrm{m}$ brain slices that included the injection site, the corpus callosum, and the target cortex were placed in culture and viewed under low-light-level conditions with a siliconintensified target (SIT) camera. Time-lapse video observations revealed striking differences in growth cone behaviors in different regions of the callosal pathway. In the tract, which is defined as the region of the callosal pathway from the injection site to the corresponding target cortex, growth cones advanced rapidly, displaying continual lamellipodial shape changes and filopodial exploration. Forward advance was sometimes interrupted by brief pauses or retraction. Growth cones in the target cortex had almost uniform compact shapes that were consistently smaller than those in the tract. In cortex, axons adhered to straight radial trajectories and their growth cones extended at only half the speed of those in the tract. Growth cones in subtarget regions of the callosum beneath cortical targets displayed complex behaviors characterized by long pauses, extension of transitory branches, and repeated cycles of collapse, withdrawal, and resurgence. Video observations suggested that extension of axons into cortical targets could occur by interstitial branching from callosal axons rather than by turning behaviors of the primary growth cones. These results suggest the

\footnotetext{
Received Mar. 5, 1993; revised Sept. 27, 1993; accepted Oct. 4, 1993.

We are grateful to Cheryl Adams for artwork and photography. We thank David Sretavan and Lea Ziskind-Conhaim for helpful comments on the manuscript, and Mark Blanton for useful technical advice. We also thank Carolyn Norris for helpful discussions in the initial phase of this work. This work was supported by NIH Grant NS14428 (to K.K.) and Training Grant GM07507.

Correspondence should be addressed to Katherine Kalil, Department of Anatomy, 255 Bardeen, 1300 University Avenue, Madison, WI 53706.

Copyright (C) 1994 Society for Neuroscience $0270-6474 / 94 / 142161-17 \$ 05.00 / 0$
}

existence of guidance cues distinct for each of these callosal regions that elicit characteristic growth cone behaviors.

[Key words: growth cone, video microscopy, corpus callosum, axon guidance, cortical development, brain slice]

During development of the nervous system, axons must often navigate over long pathways to reach distant targets. The highly motile exploratory structure at the tip of a growing neurite, the nerve growth cone, plays an active role in axonal pathfinding by responding to environmental cues. The identities of these cues are largely unknown in vertebrates. To gain insight into how growth concs respond to different environmental cues, a number of studies in both vertebrates and invertebrates have examined the morphologies of growth cones in different regions along central pathways (Raper et al., 1983a,b; Bovolenta and Mason, 1987; Nordlander, 1987; Bovolenta and Dodd, 1990; Norris and Kalil, 1990; Nordlander et al., 1991; Ghosh and Shatz, 1992) and in peripheral pathways (Bentley and Caudy, 1983; Tosney and Landmesser, 1985; Caudy and Bentley, 1986). In general, small simple growth cone shapes have been associated with tracking behaviors along other neurites or glial processes, whereas large complex forms, often characterized by multiple branches, have been correlated with regions of pathways in which the growth cone must alter its direction. These choice points have sometimes been referred to as "decision regions" (Tosney and Landmesser, 1985; Bovolenta and Mason, 1987). Nevertheless, such conclusions are based on still images of different growth cones fixed at a single point in timc, rather than sequential images of the same growth cone changing over time.

As a means to observe the dynamic behaviors of living growth cones in their natural environments, several recent studies have turned to new techniques in low-light-level video microscopy. These methods permit extended periods of time-lapse observation of fluorescently labeled growth cones extending in situ. Time-lapse video microscopy has been used on intact or semiintact preparations of vertebrate (Myers et al., 1986; Harris et al., 1987; O'Rourke and Fraser, 1990; Mason and Godement, 1991; Kaethner and Stuermer, 1992; Chien et al., 1993; Sretavan and Reichardt, 1993) and invertebrate (O'Connor et al., 1990; Sabry et al., 1991; Myers and Bastiani, 1993) neural systems. In the present study we have used these techniques to study behaviors of living dye-labeled axons and their growth cones navigating within the corpus callosum, a major CNS pathway that connects the two mammalian cerebral hemispheres. To 
make direct time-lapse video observations in regions of the developing mammalian brain that would otherwise be inaccessible to view, we have devised a unique preparation of the newborn hamster callosal pathway. The corpus callosum has a number of advantages for such studies. Most importantly, the entire pathway is contained within a narrow rostral-caudal plane (Olavarria and Van Sluyters, 1986). It originates predominantly from layers 3 and 5 of the cerebral cortex and projects across the midline to corresponding homotypic targets in the opposite hemisphere (Yorke and Caviness, 1975; Wise and Jones, 1976; Rhoades and Dellacroce, 1980; Miller and Vogt, 1984; Carvell and Simons, 1987; Koralek et al., 1990). This has permitted us to use a slice preparation through the sensorimotor cortex that includes not only the callosal trajectory of the labeled axons but also the target cortex. We have therefore been able to study and compare growth cone behaviors in all regions of the callosal system. Another advantage to this system is that in hamsters outgrowth of callosal axons from the sensorimotor cortex occurs almost entirely postnatally (Lent et al., 1990; Norris and Kalil, 1990), so labeling of the axons can be accomplished by injections of fluorescent dye into the cortex of newborn rather than embryonic animals.

We sought to characterize growth cone behaviors in different regions of the developing callosal pathway, because differences in such behaviors might reflect differences in local guidance mechanisms acting on callosal growth cones. In previous work we found that growth cone morphologies in the callosal tract were large and complex compared with smaller simpler growth cones extending radially into cortical targets (Norris and Kalil, 1990). Subsequently, we discovered that callosal growth cones in the cortex extended along radial glial processes (Norris and Kalil, 1991), a mechanism of axon guidance that could account for the small simple growth cone morphologies observed in the cortex. However, an important question that could not be addressed in fixed tissue was how callosal growth cones made the transition from tract to cortical target. Moreover, these fixed images provided little information about dynamic growth cone shape changes or about rates of outgrowth of individual growth cones.

In this study, we have therefore used time-lapse video microscopy to observe the behaviors of individual Dil-labeled (Honig and Hume, 1986) callosal axons and their growth cones extending in living brain slices from infant hamster sensorimotor cortex. Time-lapse observations during recording sessions lasting up to $14 \mathrm{hr}$ revealed striking differences in growth cone behaviors in different regions of the callosal pathway. We found that in the tract, growth concs advanced rapidly, undergoing continual shape changes. In the cortex, growth cones extending radially were smaller, advanced at only half the speed of those in the tract, and displayed a narrower range of shape changes. In regions of the callosum beneath cortical targets, growth cones exhibited dramatic behaviors characterized by cycles of collapse, withdrawal, and resurgence, as well as the extension of side branches. These observations suggest the existence of guidance cues distinct for each of these callosal regions to which growth cones respond with characteristic behaviors.

A portion of these results has been published previously in abstract form (Halloran and Kalil, 1991, 1992).

\section{Materials and Methods}

Observations of growing callosal axons were carried out in living brain slices from neonatal golden hamsters (Mesocricetus auratus) ranging from 2 to $4 \mathrm{~d}$ of age. Hamsters were born $15-16 \mathrm{~d}$ after mating. The day of birth was considered to be postnatal day 0 (P0).

Dye application. Application of the lipophilic fluorescent dye DiI (1, ' ' '-dioctadecyl-3,3,3',3'-tetramethylindocarbocyanine perchlorate; Molecular Probes, Eugene, OR) was carried out in hamsters 1-3 d of age. Animals were anesthetized by cooling on crushed ice, and a small area of the skull over one hemisphere of the sensorimotor cortex was removed with fine-tipped forceps. A small crystal of DiI was inserted into either one or two cortical sites approximately $0.5-1 \mathrm{~mm}$ from the midline to a depth of $0.5 \mathrm{~mm}$. Care was taken to avoid damage to the blood vessels. The skin over the skull was sutured and the animals returned to the nest.

Slice preparation and maintenance. Sixteen to $24 \mathrm{hr}$ following DiI application, animals were reanesthetized by cooling on ice. The brains were rapidly removed into ice-cold artificial cerebral spinal fluid (aCSF), encased in 3\% agar, and set on ice until the agar solidified. The aCSF contained $124 \mathrm{mM} \mathrm{NaCl}, 5 \mathrm{mM} \mathrm{KCl}, 1.25 \mathrm{mM} \mathrm{NaH}_{2} \mathrm{PO}_{4}, 2 \mathrm{mM} \mathrm{MgSO}_{4}$, $2 \mathrm{~mm} \mathrm{CaCl}_{2}, 10 \mathrm{~mm}$ glucose, $10 \mathrm{~mm} \mathrm{NaHCO}$, and $15 \mathrm{~mm}$ HEPES. Coronal slices $(400 \mu \mathrm{m})$ through the forebrain were cut on a vibratome (Lancer) and collected in ice-cold aCSF. The slice containing the Dil injection site was placed into the well of an open chamber fitted with a coverslip bottom. The slice was held in place by a tightly fitting ring covered with netting inserted into the well of the chamber. The slice was allowed to rest at room temperature for $30 \mathrm{~min}$, during which time $95 \% \mathrm{O}_{2} / 5 \% \mathrm{CO}_{2}$ was bubbled continuously into the chamber well. The chamber was then placed on the microscope stage and perfused continuously with Dulbecco's modified Eagle's medium (GIBCO, Grand Island, NY) at a flow rate of $3 \mathrm{ml} / \mathrm{min}$. The culture medium was heated in a water bath and bubbled continuously with $95 \% \mathrm{O}_{2} / 5 \% \mathrm{CO}_{2}$. During video imaging the slice was kept barely submerged in fluid by drawing medium away with a vacuum exhaust. The slice was allowed to equilibrate to $37^{\circ} \mathrm{C}$ before imaging began. To maintain a constant temperature around the chamber, the microscope stage was surrounded with an acetate enclosure into which was inserted an incubator blower (Nikon) that maintained the enclosure at $37^{\circ} \mathrm{C}$. Because growth cone motility was extremely sensitive to temperature, the chamber temperature was monitored with a small temperature probe (Yellow Springs Instruments, Yellow Springs, $\mathrm{OH}$ ).

Time-lapse video microscopy. Time-lapse observations were carried out on an inverted microscope (Zeiss, Axiovert 35M) equipped with a $50 \mathrm{~W}$ HBO epifluorescence light source, a rhodamine filter set, lowpower $(10 \times$ and $20 \times$ ) fluorescence objectives, and a long-workingdistance $40 \times$ objective. Video imaging was performed under low-lightlevel conditions. Neutral density filters were placed in the light path to filter out $70-95 \%$ of the light. This was important in avoiding photo damage to fluorescently labeled axons and growth cones. Infrared heat filters were also used to reduce heat damage. Images were detected with a silicon-intensified target (SIT) camera (Dage, MTI model 66) mounted onto the microscope camera port. To reduce the duration of exposure of the slice to light, an electronic shutter (Uniblitz) was placed into the light path and programmed from the computer to open for less than a second at 2 min intervals. Images were acquired and frame averaged (8-16 images) with a digital image processor (IMAGE-1, Universal Imaging, West Chester, PA), stored on laser disks with an optical memory disk recorder (OMDR; model 2028, Panasonic), and displayed on a high-resolution color monitor (Sony). During the course of the experiments, images werc played back frequently to monitor the viability and progress of growth cones, and to change the field of view when necessary. The focus was continually monitored, which ensured that changes in growth cone morphology were not the result of changes in focal plane. Photographs of growth cones were taken directly from the monitor with a $35 \mathrm{~mm}$ camera. Drawings of growth cones were traced from the monitor on acetate sheets, and aligned in sequence using a fixed point in the background.

To select growth cones for video observation, the entire callosal pathway was inspected with the $20 \times$ objective. The dorsal and medial borders of both the injected and contralateral cortical hemispheres as well as the boundaries of the corpus callosum were visible, and the slice could be surveyed rapidly without unnecessary exposure of the slice to fluorescent light. Three regions of the callosal pathway were chosen for study of growth cone bchaviors (sce Fig. 1). The first, designated the tract, is the region of the callosum extending from the injection site across the midline up to the region beneath the contralateral cortex homotopic to the injection site. The second, designated the subtarget region, refers to the area of the corpus callosum beneath the cortex 


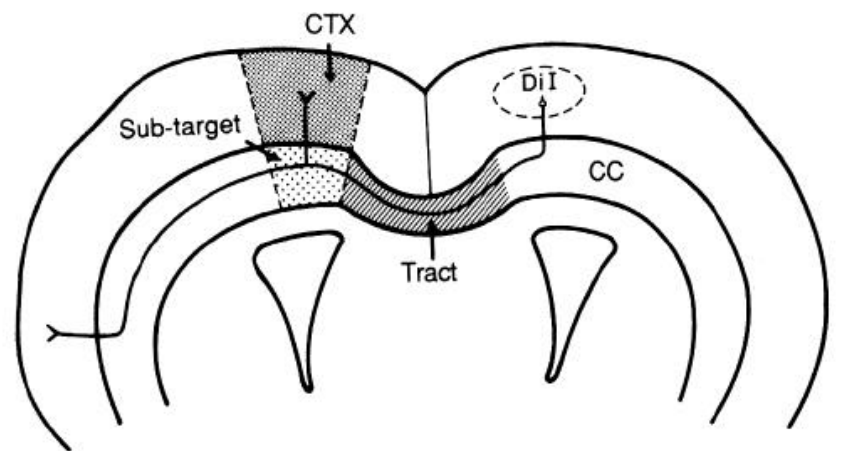

Figure 1. Schematic drawing of a typical slice preparation through the sensorimotor cortex illustrating the location of the DiI injection site and the three regions of the callosal pathway in which growth cone behaviors were observed. The tract is indicated by hatching, the subtarget region by coarse stippling, and the cortex (CTX) by fine stippling. The axon schematized in the drawing originates in the injected cortex and gives rise to a branch in the contralateral homotopic cortex. $C C$, corpus callosum.

corresponding to the location of the contralateral injection site. The third region, designated cortex, refers to cortical target regions into which callosal axons or their branches have extended. In all regions of the callosal pathway, growth cones chosen for study displayed continuous motility, even if this involved shape changes without forward advance. Beaded axons, iñdicative of degeneration, were avoided, as were growth cones in a nonmotile state. Growth cones on the surface of the slice were not considered to be in their natural environment and were not included in the data. Most of the growth cones described were about $50-100 \mu \mathrm{m}$ beneath the surface since in these focal planes resolution tended to be better than deeper within the slice. Because growth cones on axons severed from their cell bodies can show extension and motility for $2-3 \mathrm{hr}$ (see Discussion), we excluded from the data any growth cone that ceased motility during the first $3 \mathrm{hr}$ of the life of the slice. Slices in which many axons were damaged or displayed little motility were discarded. Approximately $30 \%$ of all the slices prepared were used in successful video sessions. Growth cones included in the data met all of these criteria for viability. When possible, regions of the callosal pathway that showed several motile growth cones in the field of view were chosen for imaging. The quality of the images was generally better when only a small number of axons were labeled, since there was less out-of-focus fluorescence.

Measurements of growth cone behaviors. Individual images from video sequences stored on the OMDR were copied into IMAGE- 1 in order to make measurements of growth cone rates and trajectories with the IMAGE-1 software. To determine rates, the position of the growth cone at the beginning of the sequence was superimposed on the final image of the sequence (or intermediate images for long sequences), and the total length of the axon trajectory was calculated using the "measure curve length" function. This length was divided by the total time of observation to give a value for the net overall rate of advance. The values for time spent in forward advance, pausing, or retraction were obtained by playing back sequences one image at a time and determining, for every image, whether the growth cone had advanced, retracted, or remained in the same position as in the previous image. These results were tallied, and the data expressed as the percentage of 2 min intervals in which the growth cone advanced, paused, or retracted. The differences in mean rates of advance and mean percentage of time spent in forward advance for the three regions of the pathway were analyzed for statistical significance using the Student's $t$ test.

\section{Results}

\section{Growth cone behaviors in the tract}

Earlier studies in vivo (Lent et al., 1990; Norris and Kalil, 1990) showed that axons of the developing hamster sensorimotor cortex begin to project across the callosal pathway a few hours before birth and continue to grow out in a staggered fashion during the first postnatal week. Axons do not fasciculate with originally neighboring axons but diverge widely as they extend

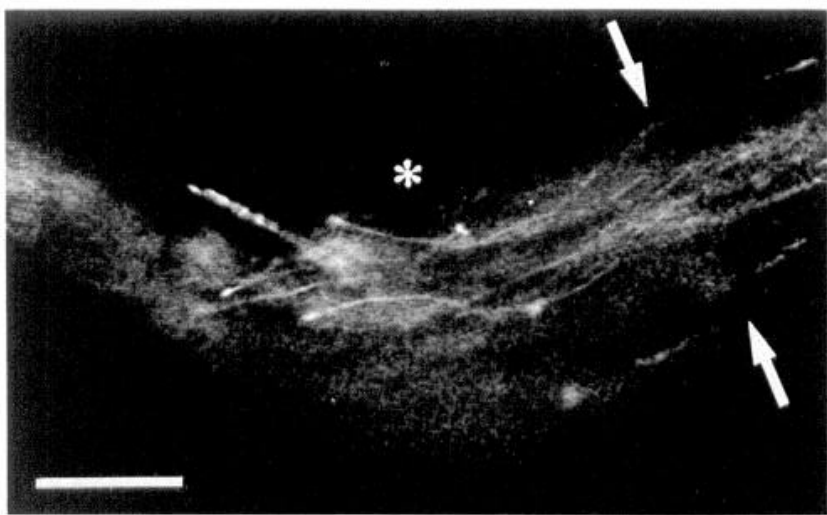

Figure 2. Single video frame taken from a low-power $(20 \times$ objective $)$ sequence of the corpus callosum in a P2 slice. Arrows denote approximate borders of the callosum and asterisk indicates location of the midline. Note independent trajectories of labeled callosal axons and growth cones within the tract. Scale bar, $100 \mu \mathrm{m}$.

across the callosum. The pattern of axon outgrowth in living slices was staggered as in vivo. At P2-P4, the ages of the slices used in the present study, the distance across the callosum between corresponding points in the sensorimotor cortices of each hemisphere is about $2 \mathrm{~mm}$ (Fig. 1). At this age, some callosal axons were still growing in the tract toward the midline of the slice while others were already beginning to enter targets in the opposite hemisphere. None of the growth cones observed at this age are the first to cross the callosum, that is, the pioneer growth cones. As in vivo, axons within the slice could undulate over large dorsal-ventral regions of the callosum, but we also observed axons growing in straight trajectories in the tract for several hours at a time. Growth cones, although generally visible up to $200 \mu \mathrm{m}$ within the slice, sometimes grew out of their narrow coronal focal plane.

To obtain an overview of the behaviors of a population of growth cones within a single slice, we first carried out time-lapse imaging at low power with the $20 \times$ objective ( $n=5$ slices). These qualitative observations are not included in the quantitative data shown in Table 1. A typical low-power image of the midline area of a slice from a P2 brain is shown in Figure 2. At this magnification the field of view includes a $560-\mu \mathrm{m}$-wide region, which is approximately $25 \%$ of the callosal trajectory at this age. At most time points during the $5 \mathrm{hr}$ period of observation for this slice, four or five axons tipped with motile growth cones were usually visible in the tract. The axons, originating from the same region of sensorimotor cortex, had highly independent trajectories. Individual growth cones also had different rates of outgrowth and showed distinct modes of advance. Some growth cones appeared to glide smoothly across the callosum while others displayed bouts of saltatory outgrowth with forward advance interrupted by pauses or retractions. On some axons transient branches tipped with growth cones appeared and withdrew.

The next series of video observations was carried out at higher magnification using the long-working-distance $40 \times$ objective to reveal details of growth cone behaviors. At this magnification, we were able to distinguish the central body of the growth cone, the thin sheet-like lamellipodium, and, in part, the spiky filopodial protrusions (Goldberg and Burmeister, 1989). In seven slices, a total of 12 growth cones in the callosal tract was observed in time lapse for 3-11 hr time periods (Table 1). In all 


\begin{tabular}{|c|c|c|c|c|}
\hline & $\begin{array}{l}\text { Net growth rate } \\
(\mu \mathrm{m} / \mathrm{hr})\end{array}$ & $\begin{array}{l}\% \text { Time spent } \\
\text { in advance }\end{array}$ & $\begin{array}{l}\% \text { Time spent } \\
\text { in pausing }\end{array}$ & $\begin{array}{l}\% \text { Time spent } \\
\text { in retraction }\end{array}$ \\
\hline \multicolumn{5}{|l|}{ Tract } \\
\hline 1 & 74 & 75.6 & 19.2 & 5.2 \\
\hline 2 & 105 & 88.4 & 8.7 & 2.9 \\
\hline 3 & 139 & 98.0 & 2.0 & 0 \\
\hline 4 & 63 & 77.4 & 14.1 & 8.5 \\
\hline 5 & 79 & 82.9 & 13.0 & 4.1 \\
\hline 6 & 92 & 96.6 & 3.4 & 0 \\
\hline 7 & 63 & 75.2 & 19.1 & 5.7 \\
\hline 8 & 73 & 82.4 & 14.7 & 2.9 \\
\hline 9 & 62 & 70.8 & 29.2 & 0 \\
\hline 10 & 55 & 66.1 & 29.8 & 4.1 \\
\hline 11 & 55 & 80.3 & 19.7 & 0 \\
\hline 12 & 75 & 85.9 & 12.8 & 1.3 \\
\hline Mean \pm SEM & $77.9 \pm 7.0$ & $81.6 \pm 2.8$ & $15.5 \pm 2.5$ & $2.9 \pm 0.8$ \\
\hline \multicolumn{5}{|l|}{ Cortex } \\
\hline 1 & 45 & 80.3 & 16.4 & 3.3 \\
\hline 2 & 70 & 88.0 & 12.0 & 0 \\
\hline 3 & 46 & 85.2 & 14.8 & 0 \\
\hline 4 & 41 & 75.0 & 25.0 & 0 \\
\hline 5 & 37 & 61.2 & 31.3 & 7.5 \\
\hline 6 & 26 & 67.0 & 25.0 & 8.0 \\
\hline 7 & 58 & 88.4 & 9.3 & 2.3 \\
\hline 8 & 58 & 84.6 & 15.4 & 0 \\
\hline 9 & 30 & 70.9 & 29.1 & 0 \\
\hline 10 & 22 & 66.6 & 16.7 & 16.7 \\
\hline 11 & 44 & 70.4 & 25.9 & 3.7 \\
\hline 12 & 44 & 78.6 & 21.4 & 0 \\
\hline 13 & 30 & 66.3 & 33.7 & 0 \\
\hline Mean \pm SEM & $42.4 \pm 4.0^{*}$ & $75.6 \pm 2.6$ & $21.2 \pm 2.1$ & $3.2 \pm 1.4$ \\
\hline \multicolumn{5}{|l|}{ Subtarget } \\
\hline 1 & 65 & 74.0 & 22.1 & 3.9 \\
\hline 2 & 37 & 48.9 & 41.7 & 9.4 \\
\hline 3 & 22 & 50.0 & 36.8 & 13.2 \\
\hline 4 & 21 & 41.7 & 44.7 & 13.6 \\
\hline 5 & 8 & 39.6 & 45.3 & 15.1 \\
\hline 6 & 34 & 54.1 & 25.9 & 20.0 \\
\hline 7 & 69 & 77.6 & 17.9 & 4.5 \\
\hline 8 & 53 & 66.3 & 16.9 & 16.8 \\
\hline 9 & 42 & 55.6 & 27.4 & 17.0 \\
\hline 10 & 25 & 47.3 & 34.5 & 18.2 \\
\hline 11 & 38 & 58.6 & 34.3 & 7.1 \\
\hline 12 & 73 & 80.5 & 15.6 & 3.9 \\
\hline 13 & 88 & 71.0 & 17.4 & 11.6 \\
\hline 14 & 38 & 51.8 & 34.9 & 13.3 \\
\hline 15 & 51 & 62.8 & 26.6 & 10.6 \\
\hline 16 & 53 & 78.8 & 19.2 & 2.0 \\
\hline 17 & 24 & 45.5 & 29.5 & 25.0 \\
\hline 18 & 2 & 42.0 & 36.7 & 21.3 \\
\hline 19 & 43 & 63.9 & 31.1 & 5.0 \\
\hline 20 & 45 & 70.5 & 24.2 & 5.3 \\
\hline 21 & 62 & 81.4 & 9.8 & 8.8 \\
\hline 22 & 79 & 70.4 & 8.7 & 20.9 \\
\hline 23 & 55 & 73.9 & 19.3 & 6.8 \\
\hline 24 & 49 & 66.2 & 21.4 & 12.3 \\
\hline 25 & 43 & 57.0 & 36.4 & 6.6 \\
\hline
\end{tabular}


Table 1. Continued

\begin{tabular}{llllc} 
& $\begin{array}{l}\text { Net growth rate } \\
(\mu \mathrm{m} / \mathrm{hr})\end{array}$ & $\begin{array}{l}\text { \% Time spent } \\
\text { in advance }\end{array}$ & $\begin{array}{l}\text { \% Time spent } \\
\text { in pausing }\end{array}$ & $\begin{array}{c}\text { \% Time spent } \\
\text { in retraction }\end{array}$ \\
\hline 26 & 33 & 58.6 & 33.3 & 8.1 \\
27 & 46 & 69.8 & 19.5 & 10.7 \\
28 & 39 & 59.4 & 20.3 & 20.3 \\
29 & 37 & 54.8 & 35.6 & 9.6 \\
30 & 66 & 87.4 & 12.6 & 0 \\
Mean \pm SEM & $44.7 \pm 3.6^{*}$ & $62.0 \pm 2.4^{* *}$ & $26.7 \pm 1.9$ & $11.4 \pm 1.2$
\end{tabular}

Rates were calculated by dividing total distance growth cone extended by total time observed. Percentage of time spent in advance, pausing, and retraction is percentage of $2 \mathrm{~min}$ intervals during which the growth cone advanced, remained in same location, or retracted.

* Significantly different from tract $(p<0.0005)$.

** Significantly different from tract $(p<0.0005)$ and cortex $(p<0.001)$.

regions of the tract examined, growth cones averaged about 10 $\mu \mathrm{m}$ in length. This was probably an underestimate because at this level of resolution, often only the initial proximal regions of the filopodia were visible, and appeared as short spikes extending from the lamellipodia. In some cases, what appeared to be complete filopodia were visible. Filopodial movements were apparent during video observations, even though they were sometimes difficult to appreciate in still frames. In regions of the tract both before and after the midline and at all ages during the 2-4 d period examined, individual growth cones displayed a wide range of dynamic shape changes during the many hours of video observation. Figure 3 shows a typical sequence at 4 min intervals of time-lapse images of a growth cone extending rapidly and steadily along the tract. In order to show clearly the dynamic morphological changes, drawings were made of the growth cone at every 2 min interval (Fig. 4). These tracings show a portion of the same sequence illustrated in Figure 3. During this sequence the growth cone displayed continuous changes in the shape of its lamellipodium but particular morphologies were not associated with either pauses or forward extension. Frequently, extension of the veil was followed by a bolus of dye-labeled material that filled the lamellipodium. This probably represents the engorgement step of axon elongation described in dissociated cells from Aplysia (Goldberg and Burmeister, 1986). Later on in this sequence (not shown), the growth cone became more streamlined and displayed small side-to-side exploratory behaviors interspersed with brief pauses.

Rates of growth cone advance in the callosal tract were highly variable, ranging from 55 to $139 \mu \mathrm{m} / \mathrm{hr}$ with a mean of $78 \mu \mathrm{m} /$ hr (Table 1). Within the same part of the tract growth cones could differ dramatically in their growth rates, as exemplified in an $8 \mathrm{hr}$ video sequence (not illustrated) in which two growth cones were observed in the region of the tract past the midline. As one growth cone extended steadily at $80 \mu \mathrm{m} / \mathrm{hr}$, a second growth cone entered the field of view and rapidly passed the first one at $139 \mu \mathrm{m} / \mathrm{hr}$. For the next several hours this growth cone continued its rapid advance and showed almost no pausing or retraction.

\section{Growth cone behaviors in the cortex}

Previous observations in vivo showed that once callosal growth cones enter their cortical target, beginning at $\mathrm{P} 2$, they become dramatically smaller and simpler (Norris and Kalil, 1990), with compact shapes only about a third the size of the large complex growth cones in the tract. Their axons were found to extend toward the cortical surface in radial trajectories (Kalil and Norris, 1991; Norris and Kalil, 1991, 1992). Observations of 13 callosal growth cones and their axons extending radially into the cortex in 11 slices confirmed and extended these results from fixed tissue. Growth cones in cortex had simple bullet shapes and were only half the size of growth cones in the tract. In comparison with growth cones in the tract, their growth rates were consistently slower, ranging from 22 to $70 \mu \mathrm{m} / \mathrm{hr}$ with a mean rate of extension of $42 \mu \mathrm{m} / \mathrm{hr}$ (Table 1), and generally exhibited more uniform morphologies and a narrower range of shape changes. Growth cones in the cortex also adhered to relatively narrow radial pathways. As shown in the sequence of images photographed from the first $92 \mathrm{~min}$ of one $5 \mathrm{hr}$ sequence (Fig. 5), and in a series of drawings (Fig. 6) traced from $38 \mathrm{~min}$ of a different sequence, growth cones entering the cortex maintained relatively uniform morphologies as they advanced slowly and steadily toward the cortical surface.

\section{Growth cone behaviors in subtarget regions}

To understand how growth cones make the transition from growing along horizontal trajectories in the tract to navigation along radial trajectories within their cortical targets, we focused on growth cone behaviors in subtarget regions of the callosum beneath the cortical target of a given callosal axon. Previous studies in vivo (Norris and Kalil, 1992) showed that callosal axons from developing hamster sensorimotor cortex innervate targets in the contralateral cortex homotopic to their points of origin. Analysis of morphologies of labeled growth cones in fixed tissue sections provided no clues to the behaviors of growth cones in transition from callosal tract to cortical target. Video observations, however, revealed complex and unusual behaviors of growth cones that were found to be characteristic of these subtarget regions. These behaviors occurred at all dorsoventral locations within the callosum under cortical targets. In contrast to the relatively steady forward advance by growth cones in the rest of the tract, those in the subtarget regions exhibited large rapid retractions and prolonged pauses in addition to periods of forward advance. For any given growth cone, the pauses were highly variable in duration. For all subtarget growth cones, pauses ranged from 2 to $38 \mathrm{~min}$. Thus, on average, these pauses were longer and more frequent (see Table 1) than for growth cones in the tract and cortex, where the pauses were no longer than 14 min. During pausing behaviors, growth cones were not dormant but continued to show motile activity without forward advance. This involved lamellar shape changes and extension 

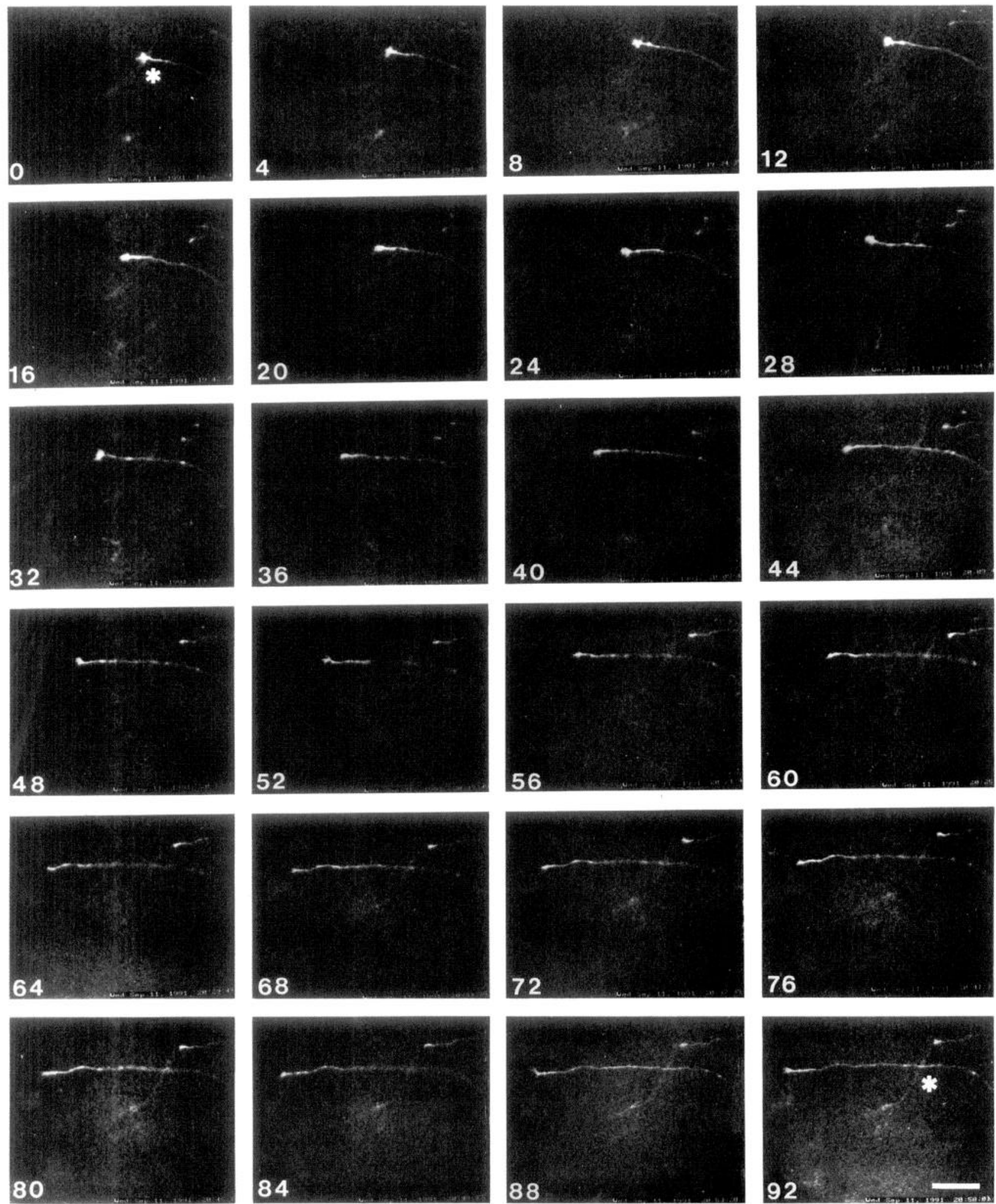

Figure 3. Time-lapse images at high power $(40 \times$ objective) of a growth cone extending within the callosal tract at P2. Images shown are at 4 min intervals. This 92 min sequence was taken from the beginning of an $11 \mathrm{hr}$ observation period for this growth cone. The first growth cone extended steadily for $142 \mu \mathrm{m}$ during the sequence illustrated $(93 \mu \mathrm{m} / \mathrm{hr})$. Asterisks in the first and last frames mark a fixed point in the background. Numbers indicate elapsed time in minutes. Scale bar, $50 \mu \mathrm{m}$. 

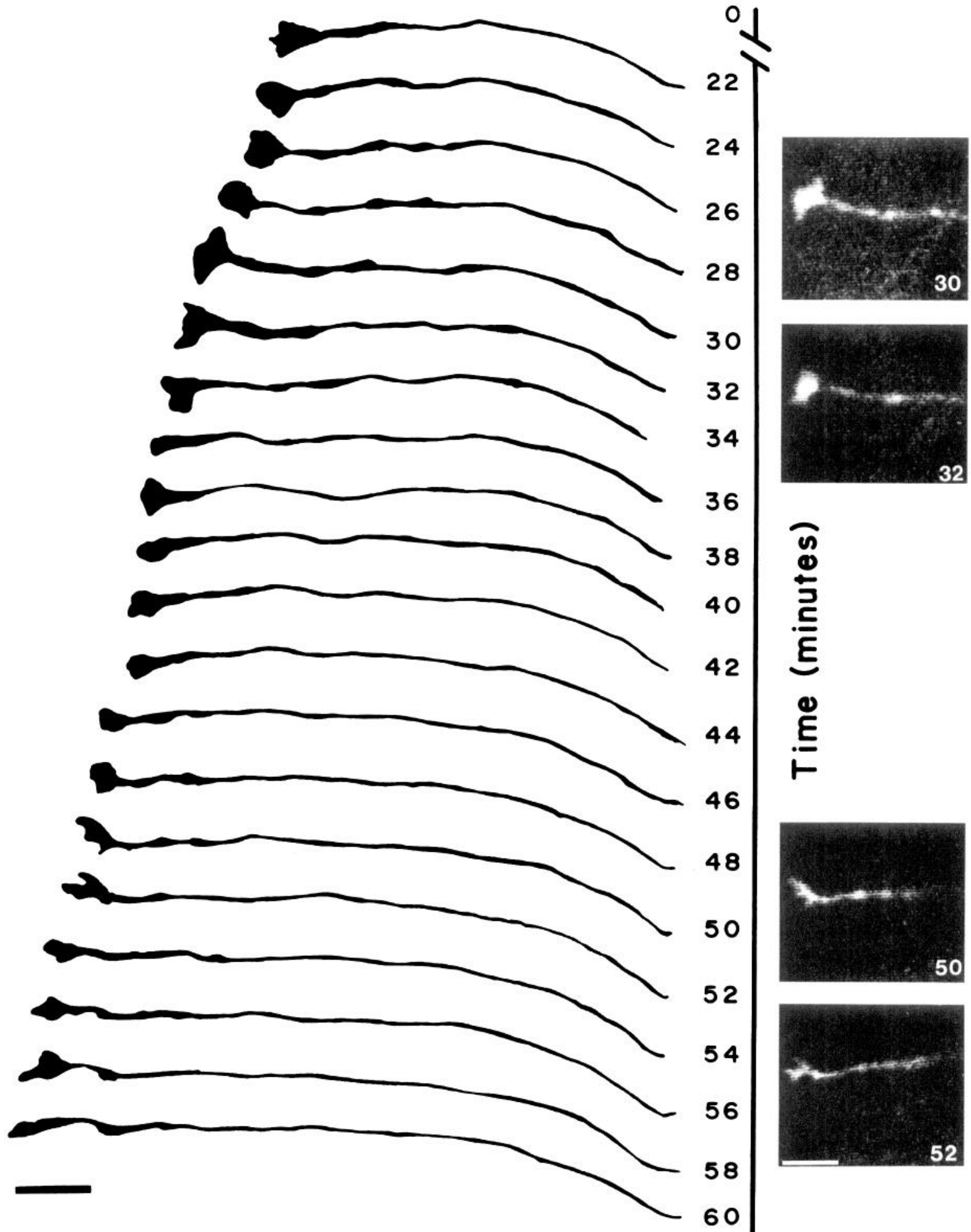

46

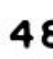

48

50

52

54

56

58
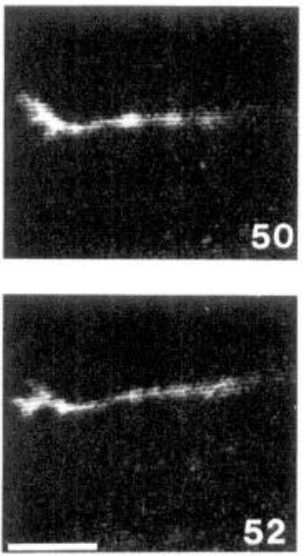

Figure 4. Series of tracings of a single axon and its growth cone extending during $38 \mathrm{~min}$ of the sequence shown in Figure 3 . Sequential drawings were made at 2 min intervals to illustrate continual lamellipodial shape changes by the growth cone in the tract during forward extension. Matching photographs at magnifications similar to drawings illustrate large dynamic growth cone shape changes. Numbers indicate elapsed time in minutes. Scale bar, $20 \mu \mathrm{m}$.

of transient protrusions from the growth cone or the proximal region of the axon.

The most dramatic behaviors in subtarget regions involved repeated growth cone collapse and retraction. In a typical se- quence, the entire growth cone would collapse and withdraw for 10-20 $\mu \mathrm{m}$. In some cases, the major part of the growth cone membrane withdrew up to $80 \mu \mathrm{m}$ back along the axon. These collapsing behaviors were extremely rapid and could occur with- 

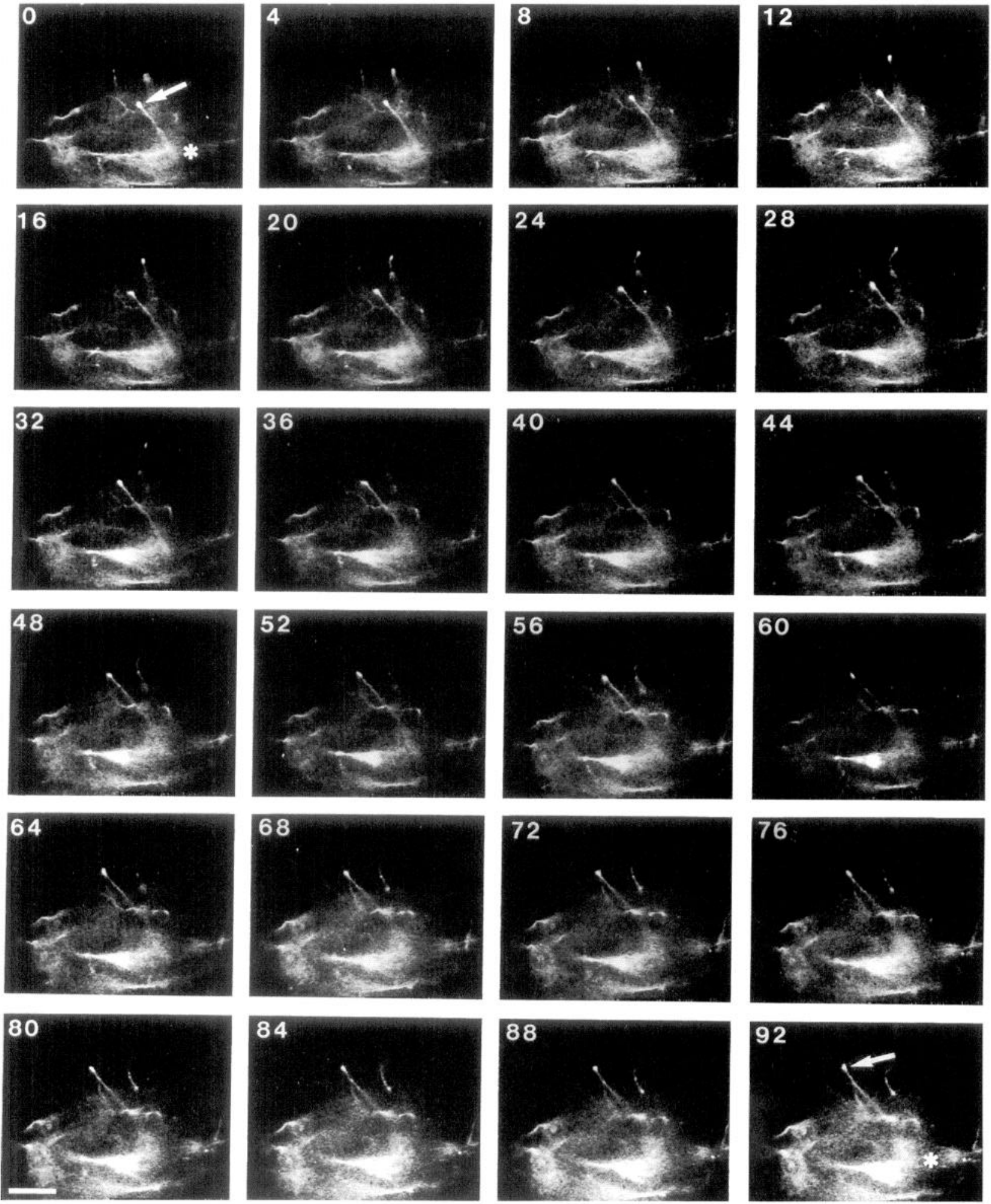

Figure 5. Time-lapse images at high power $(40 \times$ objective) of axons tipped with growth cones extending radially into cortex at P4. Images shown are at $4 \mathrm{~min}$ intervals. Growth cone indicated by arrow extended $60 \mu \mathrm{m}$ in the $92 \mathrm{~min}$ sequence shown $(39 \mu \mathrm{m} / \mathrm{hr})$. Taken from the beginning of a $5 \mathrm{hr}$ video recording session. Asterisks in first and last frames mark a fixed point in the background. Numbers indicate elapsed time in minutes. Scale bar, $50 \mu \mathrm{m}$.

in a single 2 min frame interval, although the largest retractions often required 10-15 min. When the growth cone withdrew it often left behind a long filopodial structure or a remnant of its original axon (Figs. 7,8). As the growth cone reformed, it sometimes surged back along these remnants or in some cases, as shown in Figure 8, the growth cone grew out along a new trajectory. Sometimes the original extensions remained as side branches. In subtarget regions, filopodia were also emitted from the leading edge of the growth cone, sometimes at an angle. The growth cone could then use a newly formed filopodium upon 


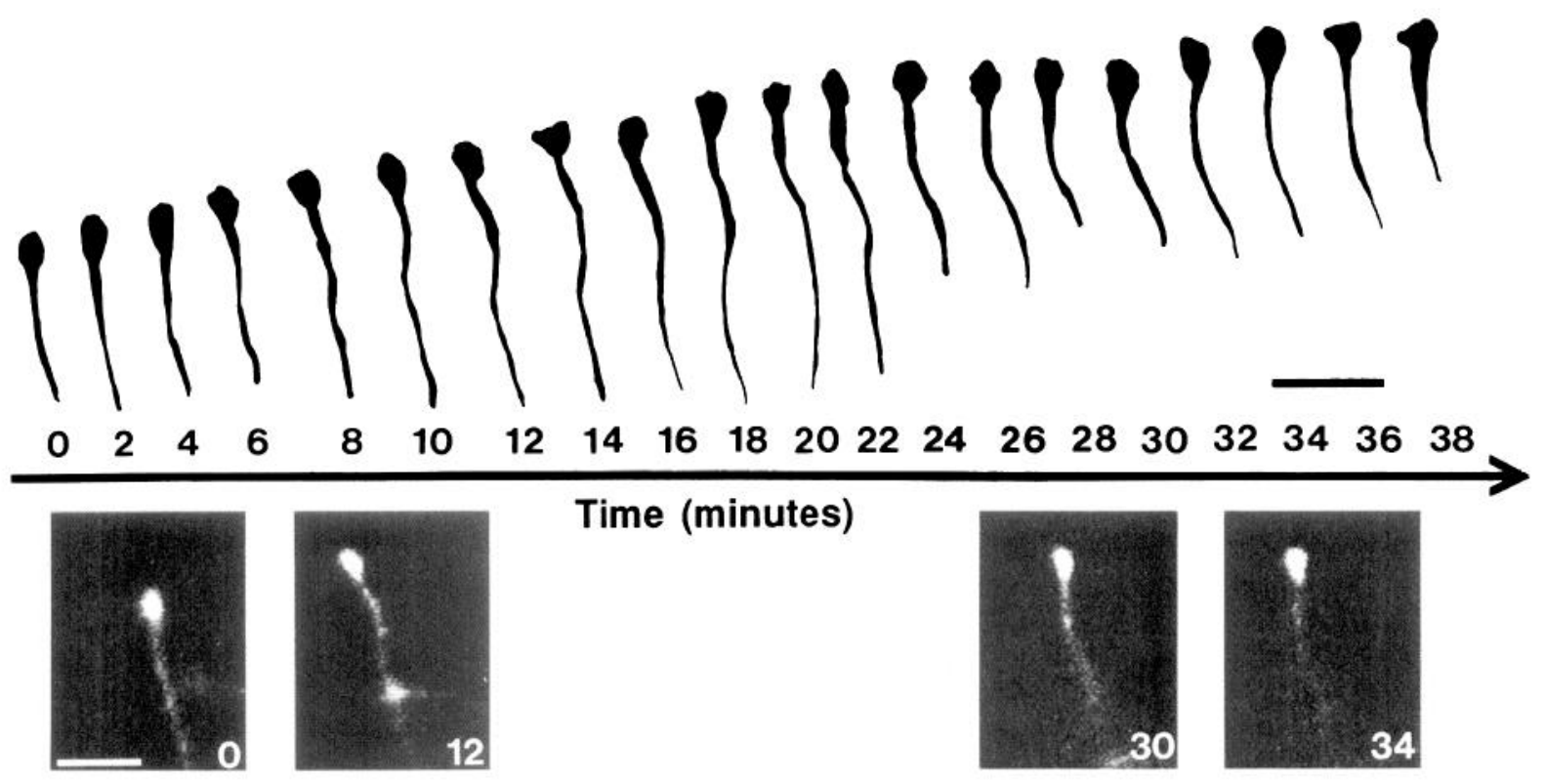

Figure 6. Series of tracings of a single axon and its growth cone (not the same as that shown in Fig. 5) extending into cortical target. Sequential drawings were made at $2 \mathrm{~min}$ intervals during $38 \mathrm{~min}$ of a $3 \mathrm{hr}$ observation period for this growth cone, which took place at the end of a $10 \mathrm{hr}$ video recording session. Slice was P3. Note slow forward advance $(58 \mu \mathrm{m} / \mathrm{hr})$ and relatively uniform morphologies compared to Figure 4. Matching photographs of select growth cones illustrate relatively small dynamic shape changes. Scale bar, $20 \mu \mathrm{m}$.

which to reorient and grow in a new direction. In time lapse, the retraction and resurgence of growth cones often resembled waves of membrane surging back and forth along the shaft of the axon. These dynamic behaviors are exemplified by the sequences shown in Figures 7 and 8, taken from regions of the tract beneath the target cortex in P3 and P4 slices. During sequences such as these, growth cones often underwent many shape changes during repeated cycles of collapse, withdrawal, pausing, and spurts of extension. Interestingly, saltatory behaviors typical of subtarget regions were often found to occur in locations where collaterals from other axons had already extended into cortex. This was true of the sequence of behaviors illustrated in Figure 8. Subsequently, as the growth cone extended beyond this region it began to advance steadily. The overall effect of these stereotypical behaviors on the trajectories of growth cones is shown schematically in Figure 9, in which the progression of typical growth cones through the tract, cortex, and subtarget regions is compared by plotting the position of the growth cone at each 2 min interval.

Quantitative analysis of the time that each growth cone spent in forward advance versus pausing and retraction (Table 1) confirmed the differences in growth cone behaviors observed in the three areas of the callosal pathway. The mean percentage of time spent in forward advance for tract growth cones was $81.6 \%$, and for cortical growth cones was $75.6 \%$. Although cortical growth cones advanced at half the rate of tract growth cones, there was no significant difference in the percentage of their time spent in forward advance, indicating that the slower overall rate of cortical growth cones was simply due to slower growth cone movement. In contrast, the slower net rate of advance in the area beneath the cortical targets $(44.7 \mu \mathrm{m} / \mathrm{hr}$ vs $77.9 \mu \mathrm{m} / \mathrm{hr}$ in the tract) was the result of numerous pauses and retractions. The intervening spurts of forward advance were often very rapid, up to $125 \mu \mathrm{m} / \mathrm{hr}$. In this area, the mean percentage of time spent in advance was $62 \%$, a value significantly different from that in the rest of the tract and in the cortex. Thus, the result of the behavioral differences was that callosal growth cones, upon entering the subtarget region, remained in one site for a longer period of time, often advancing and retracting over the same location numerous times. We compared growth cone behaviors in subtarget regions of the callosal tract versus regions of the tract beneath medial nontarget cortex. Behaviors of growth cones underneath nontarget cortex were the same as in other regions of the tract, and were characterized by rapid steady forward advance. We have therefore concluded that the complex behaviors observed in subtarget regions are unique to this part of the callosal pathway and do not occur in other parts of the callosal tract under nontarget cortex.

Another characteristic behavior of growth cones in subtarget regions was the extension of numerous, often transient side branches. These branches sometimes formed during retractions, as described above, but could also form de novo from the sides of the growth cone or from the axon just proximal to the growth cone. As shown in Figure 7, small growth cones were sometimes visible at the ends of these side branches. Almost two-thirds of the growth cones examined in the subtarget regions extended branches, whereas only four of the 12 growth cones in the tract and none of those entering the cortex showed any side branches.

A major goal in observing growth cone behaviors in subtarget regions was to determine how callosal growth cones entered the cortex. However, in the total of 30 growth cones from 24 slices imaged in these regions, we never saw a callosal growth cone make a sharp right angle turn and enter the cortex, even in video recording sessions lasting up to $10 \mathrm{hr}$ and covering a large portion of the subtarget region. Of 30 growth cones imaged in this region, 10 grew through at least $60 \%$ of the distance along the subtarget region during the video recording session. Other growth cones covered a smaller net distance through this region because they often extended back and forth over the same area several times. In one instance, we did see a growth cone bifurcate (Fig. 

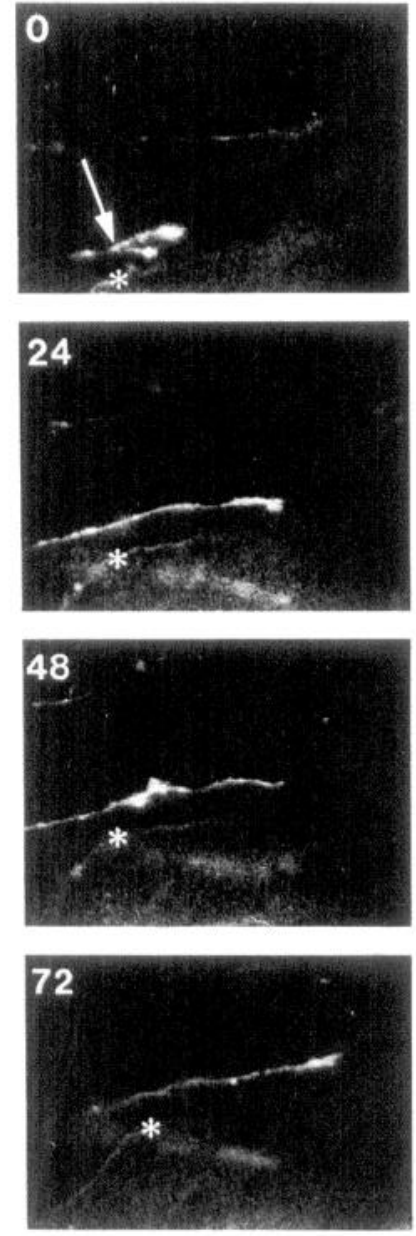
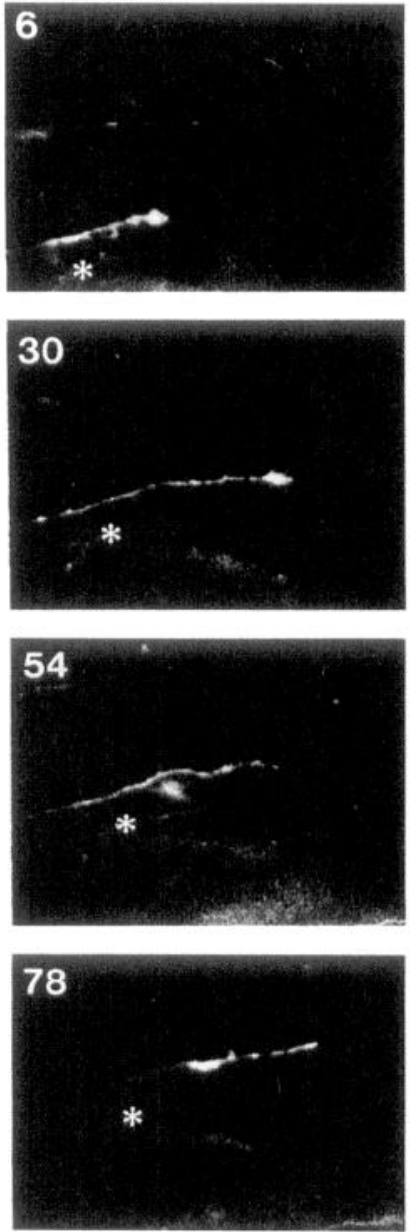
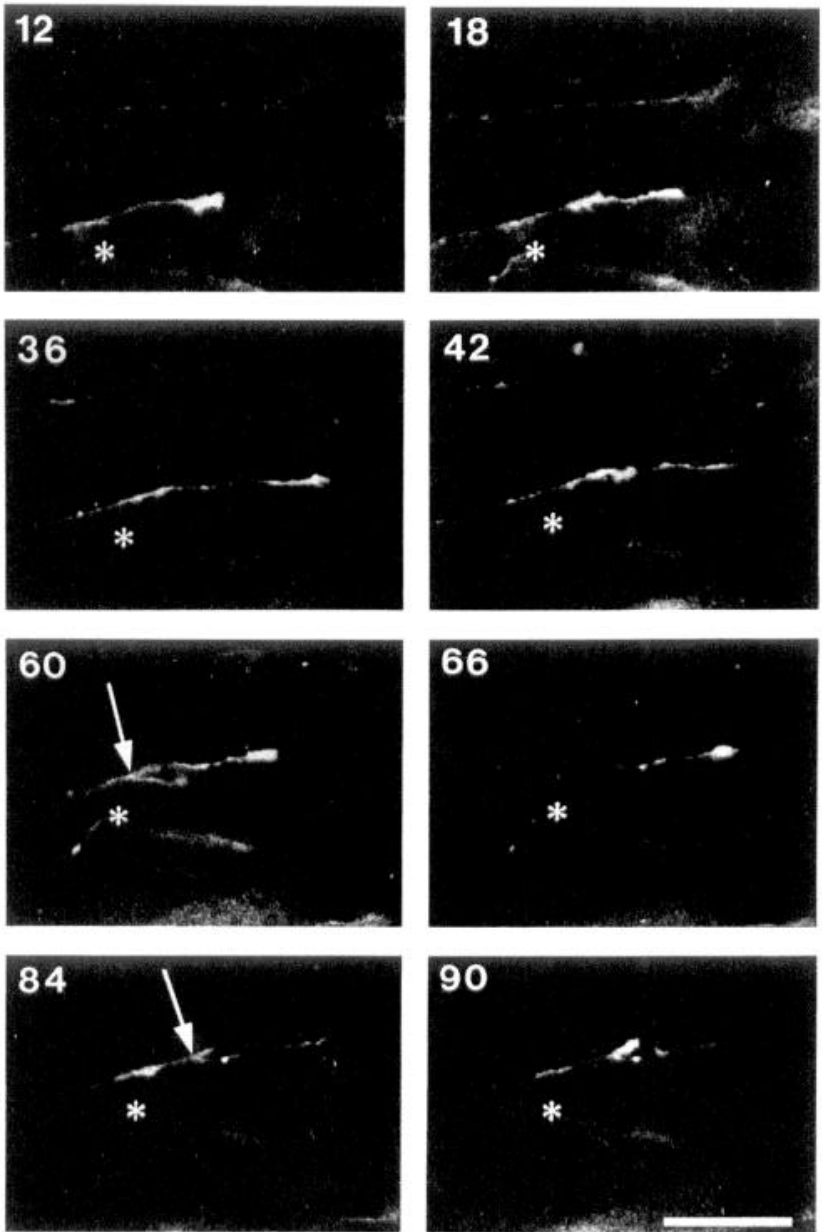

Figure 7. Time-lapse images at high power $(40 \times$ objective) of a growth cone advancing, retracting, and branching in the subtarget region of the callosum in a P3 slice. Images shown are at 6 min intervals. This 90 min sequence was part of a 3 hr observation period. The sequence begins with formation of a transient side branch (arrow) tipped with a growth cone at 0-12 min. At 42-48 min the growth cone membrane is retracting back along the axon. At 54-60 min the growth cone is resurging toward the tip of the axon, concomitant with formation of another transient side branch (arrow) from the axon. This process is repeated at $78-90 \mathrm{~min}$. Asterisks mark the same fixed point in each frame. Scale bar, $50 \mu \mathrm{m}$.

$10)$, sending one branch dorsally toward the cortex while the other branch continued to extend in the tract. Six hours after the bifurcation, the branch remaining in the tract was still advancing laterally while the cortical branch continued to grow in the dorsal direction. Although this branch was extending in the radial direction, it grew onto the surface of the slice shortly after the bifurcation, making its subsequent behavior difficult to interpret. None of the other growth cones in the subtarget region turned into the cortex. Instead, they all remained in the tract, often continuing to extend laterally.

How, then, do callosal axons enter their cortical targets? When we examined callosal axons whose growth cones had already extended laterally past the subtarget region, we frequently observed small axon collaterals sometimes tipped with growth cones extending dorsally from the primary axon beneath the target cortex. Many of these collaterals showed membrane activity without any significant advance. They appeared to be dormant, and by the end of the observation period had not yet advanced into the cortex. Others were actively extending toward the cortex. In one case shown in Figure 11, we observed a growth cone in close proximity to the branch point (first frame, Fig. 11). By the end of the sequence, the branch had grown approximately $40 \mu \mathrm{m}$ toward the cortex. This sequence suggests that we were observing the early stages in development of an interstitial collateral. Although in most cases we did not observe directly the earliest stages of collateral formation, for nine of 13 axons growing into the cortex we were able to follow the collateral back to a branch point from the parent callosal axon that had continued laterally in the tract. It is therefore possible that callosal axons entering the cortex may arise by the process of interstitial branching from a parent axon in the tract, rather than by turning behaviors of the primary growth cone. This mode of branching may occur either by new growth cone activity along an axon or by reactivation of a dormant process that is left behind by the primary growth cone after it has extended past this region.

\section{Discussion}

We have used time-lapse video microscopy to make direct observations of fluorescently labeled callosal growth cones extending in situ in living newborn hamster brain slices. These observations revealed aspects of growth cone behaviors characteristic of specific regions of the callosal pathway that could not be deduced from still images of fixed growth cones.

Callosal growth cones in the tract advanced rapidly, displaying continual lamellipodial shape changes from large fan-like 
morphologies to streamlined forms. Filopodia extended and retracted during exploratory behaviors. Forward extension was sometimes interrupted by brief pauses or retraction.

Growth cones entering the cortex had almost uniform compact shapes that were consistently smaller than those in the tract. In the cortex, growth cones and their axons adhered to relatively straight radial trajectories and growth cones extended at only half the speed of those in the tract.

Growth cones in regions of the callosum beneath their cortical targets displayed complex behaviors during which they paused for long periods of time, emitted transitory branches, and went through repeated cycles of collapse, withdrawal, and resurgence. We never obscrved primary growth cones turning to enter the cortex but did observe collateral branches extending from the callosal axon and growing dorsally toward the cortex.

\section{Validity of the method}

Because these observations were made in brain slices as opposed to the brains of living, intact embryos (Harris et al., 1987; O'Rourke and Fraser, 1990; Kaethner and Stuermer, 1992; Chien et al., 1993), it was important to be certain that behaviors of growth cones in the slice were normal and did not reflect effects of injury. A potential source of injury to living DiI-labeled neurons and their processes is exposure to fluorescent light (Kaethner and Steurmer, 1992), which can cause photodamage over time. The low light levels and brief intermittent exposure periods used in these experiments were intended to minimize such damage. When growth cones were highly motile, we considered it unlikely that they suffered from photodamage, for several reasons. First, we would expect that over the course of the video recording period, damaged growth cones would gradually slow down and cease motility. Instead, even after transient pauses, growth cones at the end of a 10-12 hr recording session were often extending just as rapidly as at the beginning, which also suggests that the culture conditions in which the slices were maintained were supportive of robust axon outgrowth. Moreover, growth cones in the tract, cortex, and subtarget regions consistently displayed behaviors characteristic for these locations regardless of whether the observations were made at the beginning or the end of the recording session. This argues against the possibility that the slice is simply running downhill over time, a consideration especially important in interpreting the cycles of advance and retraction in subtarget regions, which might be attributable to dying axons. Another observation arguing against gradual decline of the slice over time is that in one slice our initial survey revealed that growth cones were present only in the tract and not in the cortex, but after several hours in culture, a number of axons had entered the cortex and were extending radially. One such cortical growth cone is shown in Figure 6. This de novo extension of axons into the cortex during the course of the experiment suggests that conditions were suitable for robust axon outgrowth in the slice.

In addition to the possibility of artifacts arising from light damage or poor culture conditions, one must consider the effects of direct damage during the preparation of the slices. Callosal axons maintain a fairly narrow coronal plane in their trajectory from one hemisphere to the other. Nevertheless, when slices are cut on the vibratome, many axons, especially those close to the surface, will be damaged or severed from their cortical cell bodies. Video observations in the retinotectal pathway of embryonic Xenopus (Harris et al., 1987) have shown that growth cones deliberately severed from their cell bodies can continue to elon-

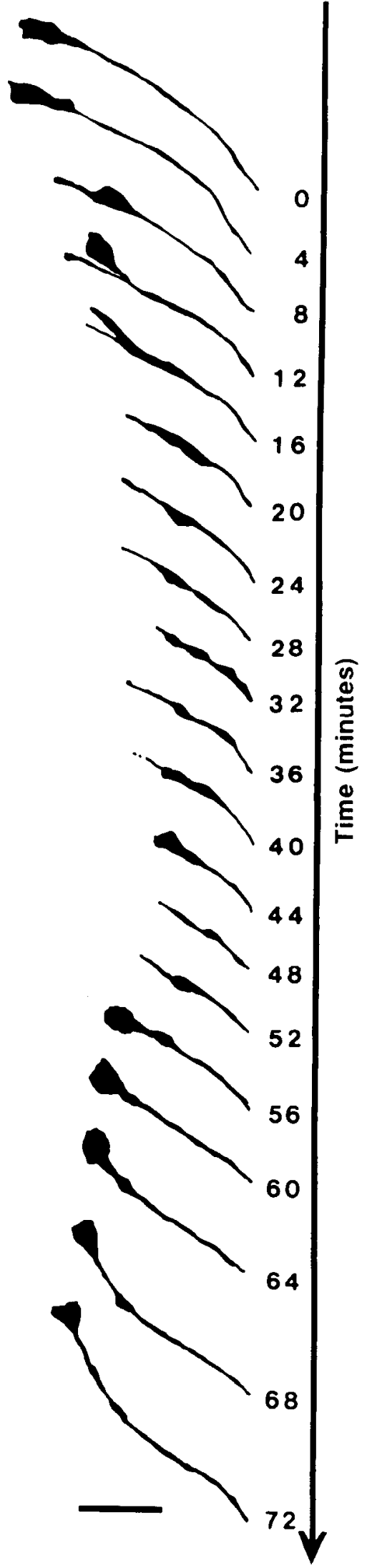

Figure 8. Series of tracings of a single axon and its growth cone in the subtarget region of the callosum in a P4 slice. Sequential drawings were made at 4 min intervals during $72 \mathrm{~min}$ of a $5 \mathrm{hr}$ recording session. The growth cone initially withdraws along its axon and then resurges in a new orientation. Scale bar, $20 \mu \mathrm{m}$. 

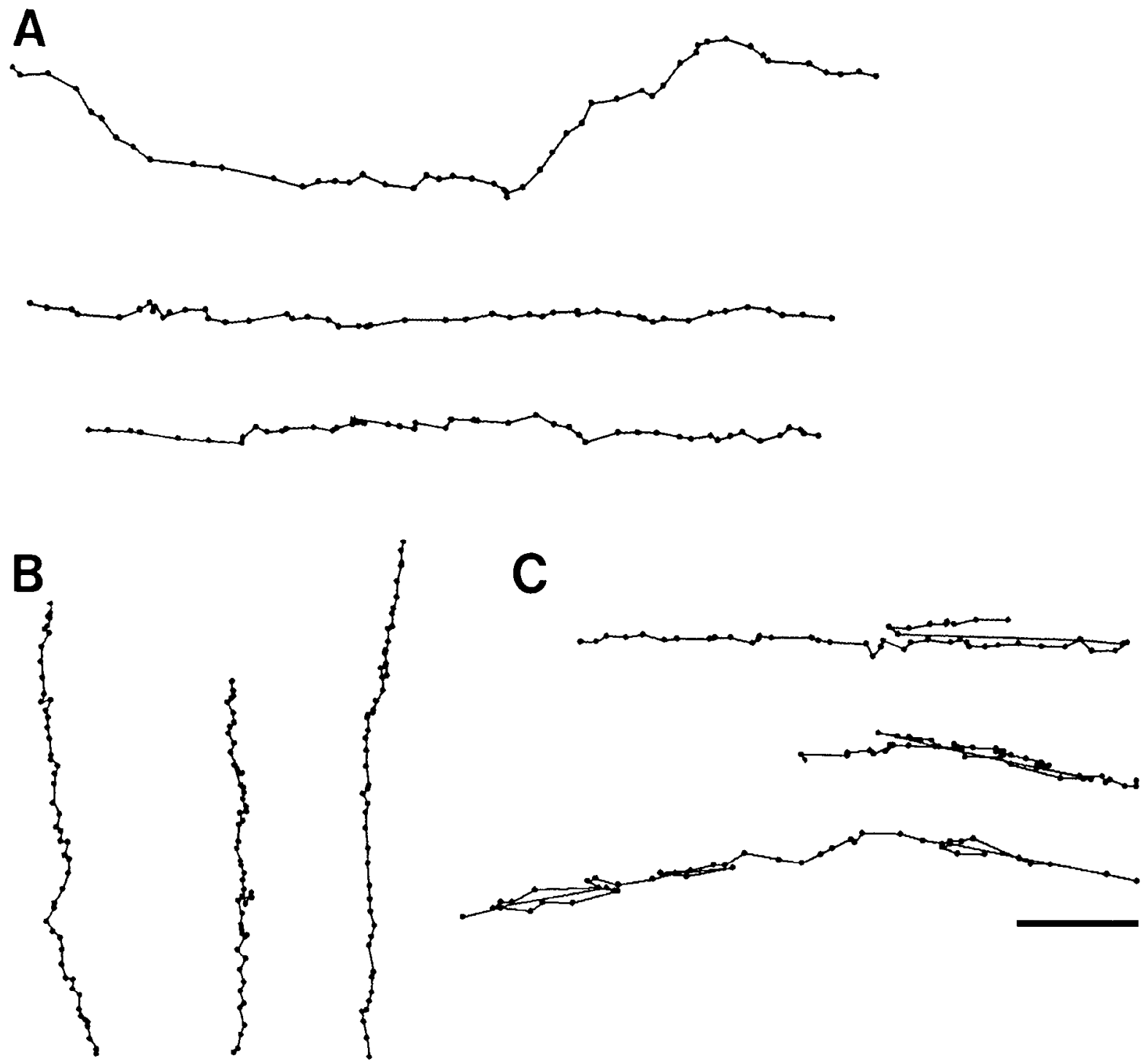

Figure 9. Graphic representations of $100 \mathrm{~min}$ segments of typical growth cone trajectories in the callosal tract $(A)$, the cortex $(B)$, and the subtarget region $(C)$. Dots represent position of growth cone center at each 2 min interval. In $A$ and $C$ the direction of forward extension is to the left. Note differences in rates of growth cone extension and, in subtarget regions, repeated extension and retraction. Scale bar, $20 \mu \mathrm{m}$.

gate for up to $3 \mathrm{hr}$. We also observed that some growth cones moving and advancing in a seemingly normal fashion for $2 \mathrm{hr}$ were later found to belong to severed axons. Therefore, we excluded from the data any growth cones whose motility was limited to the first $3 \mathrm{hr}$ of the recording session. Another population of growth cones excluded from the data are those that had escaped from the tissue and were growing along the surface of the slice as determined by their focal plane. These growth cones often grew in inappropriate directions in the tract, such as making right angle turns down toward the ventricle, or grew within the cortex at right angles to the radial axis instead of parallel to other radially aligned axons. Growth cones on the surface of the slice also had unusually spiky filopodial morphologies, in contrast to the smoother lamellipodial forms of those within the slice, and made random flailing movements on the surface as if unconstrained by the confines of their normal three-dimensional environment.

We cannot entirely rule out the possibility that artifacts of the slice preparation may have affected the behaviors of some of the growth cones observed in video microscopy. However, in the several hundred slices prepared for these experiments, growth cone motility was usually all or none. Either a number of growth cones continued robust activity for at least several hours or else no growth cone motility or extension was detected. Therefore, it does not seem likely that the dynamic saltatory growth cone behaviors in subtarget regions or the slower rate of growth cones in cortex could be attributed to damage artifacts. Furthcrmorc, rcpeated observations of growth cone behaviors specific to different regions of the callosal pathway and the consistency of the present results with previous findings from developmental studies of both the callosum and other vertebrate CNS pathways support the validity of our methods. Images from fixed material revealed smaller simpler growth cones in cortex versus larger more complex morphologies in the tract (Norris and Kalil, 1990) as shown in the present study. Our previous estimates of rates of growth cone extension in the callosal tract in vivo (about $60 \mu \mathrm{m} / \mathrm{hr}$ ) are also close to the average growth rate of $78 \mu \mathrm{m} / \mathrm{hr}$ arrived at by direct observation, and were 

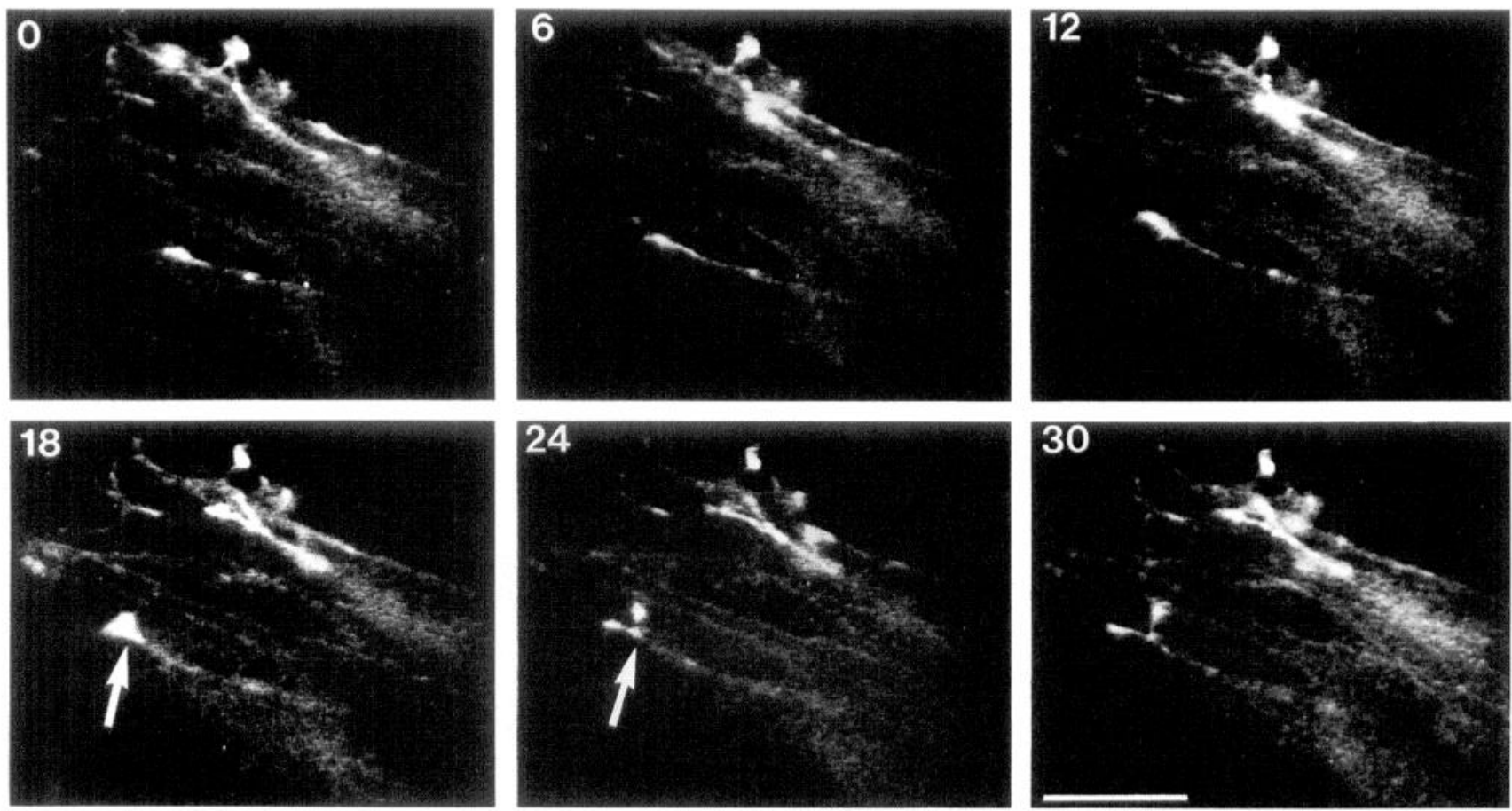

Figure 10. Time-lapse images at high power $(40 \times$ objective) of a growth cone bifurcating (arrow) in the subtarget region at P3. Images shown are at $6 \mathrm{~min}$ intervals. Sequence was taken from an $8 \mathrm{hr}$ video session. Numbers indicate time elapsed in minutes. Scale bar, $50 \mu \mathrm{m}$.

similar to growth rates reported in live video studies of other mammalian CNS pathways (Mason and Godement, 1991; Sretevan and Reichardt, 1993). Callosal growth cones in vivo also slowed down their growth rates considerably as they entered cortical targets (Norris and Kalil, 1990), consistent with the present results and those from other CNS pathways in which growth cones slow down when they encounter their targets (Harris et al., 1987; Baird et al., 1992).

\section{Interpretation of different behaviors}

Direct video observations of individual callosal growth cones have provided new information about behaviors of growth cones in their natural CNS environment. The power of direct video observations versus interpretation of fixed material is that we can follow the dynamic shape changes of the same growth cone over long periods of time. This allowed us to demonstrate di-
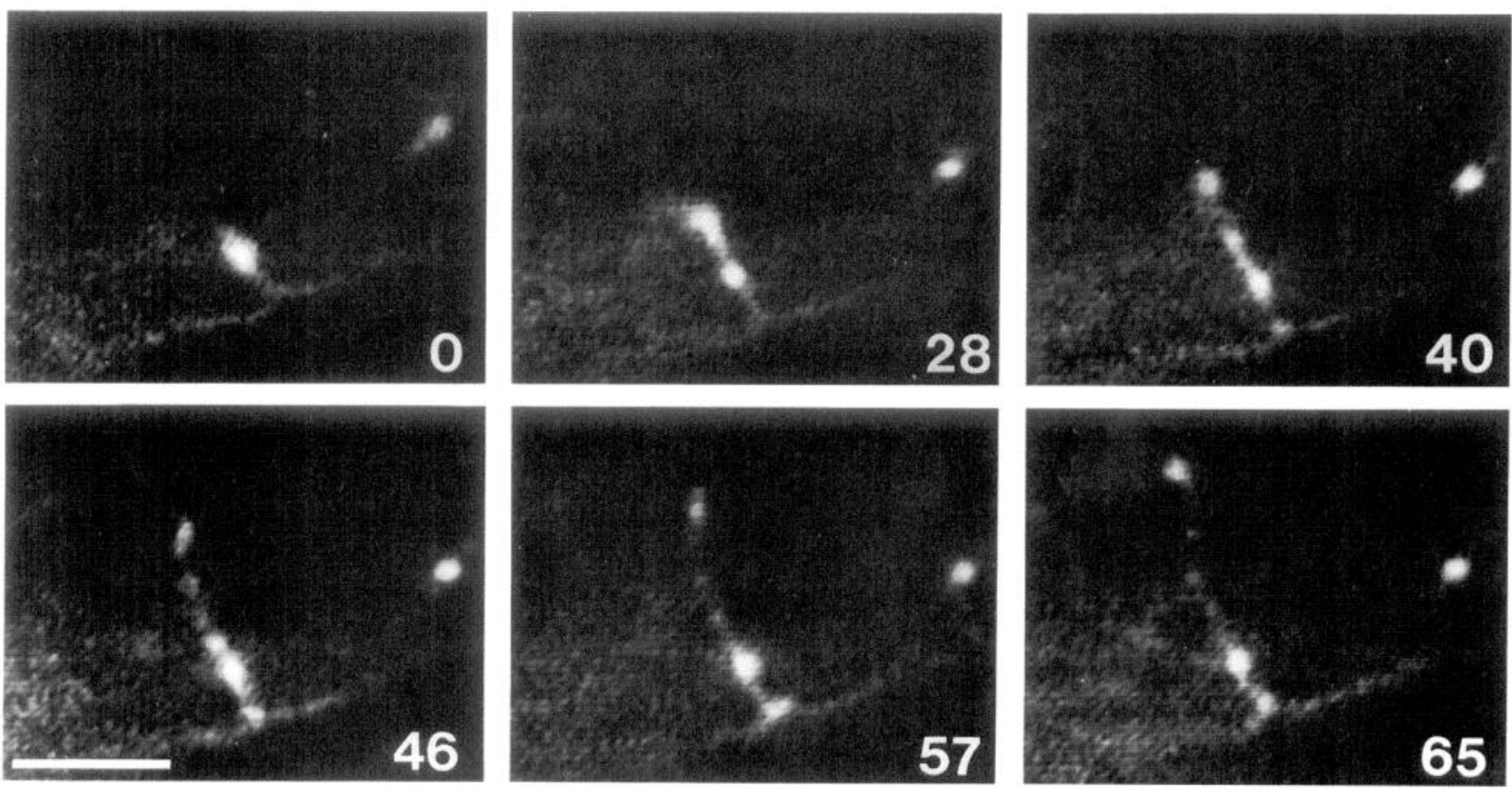

Figure 11. Time-lapse images of an axon collateral developing and extending dorsally from an axon in the subtarget region at P3. The primary growth cone of this axon has already extended well beyond the subtarget region. Time elapsed in minutes is indicated in each frame. Scale bar, $20 \mu \mathrm{m}$. 
rectly that individual growth cones undergo dynamic shape changes characteristic of their position along the callosal pathway. Second, even within the same region of this CNS pathway, different growth cones can have very different rates of forward extension. The callosal slice preparation offers the advantage of permitting comparisons of growth cone behaviors in every region of a single neural pathway. Thus, we have been able to show that callosal growth cones display dramatically different behaviors in response to cues in different regions of the same pathway.

Growth cone behaviors characteristic of different regions of the callosal pathway suggest that in each of these regions growth cones are responding to distinct guidance cues. In the tract itself the observation of large complex growth cones exploring independent pathways argues against a mechanism of guidance by fasciculation of growth cones with nearest neighboring axons, since growth cones fasciculating on other axons are typically small with streamlined morphologies (Raper et al., 1983a; Bovolenta and Mason, 1987; Nordlander et al., 1991). Instead, the broad, continually changing lamellipodial morphologies and independent trajectories of growth cones in the corpus callosum suggest that they may be responding to guidance cues that are not restricted to any particular cellular processes. In support of this supposition, callosal growth cones were found ultrastructurally (Norris and Kalil, 1990) to contact a variety of cellular processes. Similarly in Xenopus, retinal axons navigating in the absence of earlier axon tracts are appropriately guided by cues broadly distributed over the neuroepithelium (Cornel and Holt, 1992).

Behaviors of callosal growth cones and their axons within cortical targets as observed in the present study are entirely consistent with an axon guidance mechanism whereby callosal growth cones track along the processes of radial glia. Electron microscopy of serially sectioned HRP-labeled callosal growth cones demonstrated that from their point of entry to the tip of the growth cone, callosal afferents within the corlex of P2-P3 hamsters were continuously apposed to the same fascicle of radial glial processes (Norris and Kalil, 1991). Growth cones tightly fasciculated with and tracking along glial processes would be expected to have smaller simpler morphologies and to exhibit smaller ranges in dynamic shape changes, as our results have shown. The consistently straight radial trajectories of callosal axons in cortex and the complete absence of branching at early postnatal ages may reflect initial guidance by radial glia that establishes thcir radial territories in cortex before lateral arborization begins. The slowing in axonal growth rate may be due to the need to wait for cortical target areas to mature (Gotz et al., 1992), the greater density of the cortical tissue as opposed to the tract, or high adhesivity of growth cones to radial glial fascicles.

Dramatic changes in behaviors of growth cones entering the region of the corpus callosum beneath their targets suggest that they are encountering a new set of guidance cues in response to which they pause in their forward extension and go through repeated cycles of collapse, withdrawal, and resurgence. Growth cones in these regions may be responding to inhibitory cues that arrest their advance, allowing them to pause and interpret molecular cues marking the transition region for that axon from callosal tract to cortical target. The complex branching behaviors of growth cones in these regions may indicate an attempt to sample and explore as large an area of the local environment as possible. Because these regions are ultimately the choice points for entry of callosal axons into cortex, we suggest that for any given growth cone the subtarget region is a "decision region."

In other putative "decision regions" of the nervous system requiring a growth cone to change direction or join a new pathway, such as in the grasshopper CNS and periphery (Raper et al., 1983a; Caudy and Bentley, 1986), the peripheral nerve plexus of the chick (Tosney and Landmesser, 1985), the mouse optic chiasm (Bovolenta and Mason, 1987; Godement et al., 1990), or the Xenopus retinotectal system (Harris et al., 1987), growth cones were found to have highly complex morphologies. They often displayed multiple branches, in contrast to their simpler shapes along axon tracts. Recently, direct video observations of growth cones in situ in the grasshopper limb bud (O'Connor et al., 1990; Bentley and O'Connor, 1991) showed that as growth cones reached a new set of guidance cues at the limb segment boundary they chose new directions by extending several transient branches, one of which established the new trajectory. Similarly, video observations of growth cones in the CNS of grasshopper showed that one branch can establish a new trajectory for the growth cone (Myers and Bastiani, 1993). In the callosum, growth cones can also change their orientation by extending along a newly formed branch. At the mouse optic chiasm (Mason and Godement, 1991; Sretavan and Reichardt, 1993) time-lapse video microscopy revealed complex behaviors of retinal growth cones responding to cues instructing them to make a choice between crossing or remaining ipsilateral in the visual pathway. These pathway choices at the chiasm often involved extension of transient branches, similar to our observations in "decision regions" of the callosum.

\section{Role of growth cone collapse at decision regions}

An important aspect of callosal growth cone behaviors in decision regions is their repeated cycles of collapse and recovery. Growth cone collapsing behaviors have been observed in dissociated culture systems and have been postulated to serve as a mechanism to inhibit growth cones from extending into inappropriate pathways and targets (for reviews, see Patterson, 1988; Walter et al., 1990; Davies and Cook, 1991; Goodman and Shatz, 1993). For example, retinal growth cones encountering the disparate neurites of sympathetic neurons were found to collapse upon contact (Kapfhammer et al., 1986; Kapfhammer and Raper, 1987). The degree to which such collapsing behaviors play a role in guidance decisions in vivo is unknown. Similar growth cone collapsing behaviors have also been observed in situ in locations where axons are inhibited from crossing the midline. For example, at the mouse optic chiasm retinal growth cones, observed with video microscopy, exhibited repeated cycles of pausing, retraction, and advance (Mason and Godement, 1991; Sretavan and Reichardt, 1993). Axon guidance in this region may involve inhibition by a population of midline glial cells (Mason and Godement, 1991). In the grasshopper CNS a local inhibitory barrier at the midline has also been thought to induce temporary retractions in certain growth cones (Myers and Bastiani, 1993).

Our results suggest that growth cone collapse is a common occurrence in decision-making events. Whereas previous studies have stressed collapse as an inhibitory mechanism to prevent axon extension into inappropriate regions of the nervous system, our observations suggest a novel role for growth cone collapse. Collapsing behaviors of callosal growth cones may serve to temporarily arrest them in "decision regions" in order to allow growth cones to respond to local cues beneath cortical targets. 
Thus, growth cones pausing in "decision regions" could be responding to "stop-growing signals" that designate appropriate target regions. Such signals have been proposed to arrest cerebellar growth cones at their target cells in explant cultures (Baird et al., 1992). In the developing cerebral cortex the nature of such signals is unknown. Thalamocortical afferent axons may be guided into appropriate cortical target locations by interactions with subplate neurons (Ghosh et al., 1990; Ghosh and Shatz, 1992). Perhaps interactions of callosal growth cones with processes of subplate neurons may signal appropriate "stop" regions for callosal afferents, which results in growth cone pausing behaviors beneath cortical targets. Another possible guidance substrate to signal the presence of "decision regions" for individual callosal growth cones is the population of radial glial processes in the developing cortex. It is well established that radial glia provide the scaffold for migration of cortical neurons (Rakic, 1971, 1972, 1988; O'Rourke et al., 1992) and may also serve to guide radial extension of callosal axons into the developing cortex (Norris and Kalil, 1991). At early postnatal ages glial processes extend up through the callosum and the cerebral cortex (Rakic, 1972; Misson et al., 1988; Gadisseux et al., 1989; Edwards et al., 1990). We have observed that the complex growth cone behaviors characteristic of decision regions can occur at all dorsoventral locations in the callosum beneath cortical targets. This suggests that growth cones are responding to a cue located throughout the dorsoventral extent of the callosum. It is therefore possible that growth cones extending along the callosum may respond to cell surface cues on specific glial processes that they encounter in the callosal tract, signaling their arrival at appropriate target regions. Such signals may elicit transient branching from the growth cone, leading to eventual development of a collateral branch that grows toward the cortical target. In support of this notion, astroglia from appropriate target regions have been shown to provide specific cues to which afferent axons respond (Qian et al., 1992). Preliminary observation with highresolution video microscopy has shown that growth cones of dissociated embryonic cortical neurons in culture can be selectively inhibited by contact with glial cell processes that induce collapse and withdrawal of the growth cone (Lu and Kalil, 1992). At present the mechanisms by which such cues might induce the growth cone to undergo the complex behaviors observed in subtarget regions are unknown, nor is it clear whether the same cues might also influence the development of interstitial branches from callosal axons. It is also possible that extension of interstitial branches could be influenced by diffusible cues from cortical targets. The fact that complex growth cone behaviors and interstitial branching of nearby axons both occur in the same subtarget location suggests that these two phenomena may be related and may reflect recognition of appropriate target signals.

\section{Interstitial branching}

Observations in fixed tissue of callosal connectivity during development suggest that many callosal axons that enter the cortex are side branches of primary axons in the callosal tract (Hogan and Berman, 1990). In our experiments, examination of slices subsequently fixed after termination of video recording showed that most of the axons entering cortex could be traced back to right angle branch points on callosal axons that had extended laterally beyond the branch point. Direct video observations suggest two mechanisms by which side branches can form, either by bifurcation of the primary growth cone or by new growth cone activity along the parent axon. Regardless of how these side branches form, we consider that extension of callosal axons into cortex is likely to occur by side branching. We cannot rule out the possibility that the primary growth cone itself turns into the overlying cortex. However, it seems unlikely that in over 30 lengthy recording sessions covering a significant cxtent of the subtarget region we would never capture turning behaviors by growth cones in decision regions if such behaviors were common. Previous studies of target innervation in vertebrate pathways both in vivo and in vitro have shown that interstitial budding as described in the rat corticopontine system (O'Leary and Terashima, 1988; Heffner et al., 1990) may be a common mechanism in the development of CNS pathways such as the frog retinotectal system (Harris et al., 1987). Interstitial budding occurs from axons whose primary growth cones have already grown past the target (O'Leary and Terashima, 1988) and delays in the formation of these side branches may actually account for the "waiting periods" during which axons in the mammalian CNS have been thought to wait beneath their targets before innervating them. In the hamster corpus callosum, the emergence of side branches only a short distance behind the growth cone suggests that these waiting periods may be very short even though the side branches may take a week to extend the full distance through the developing cortex (Norris and Kalil, 1992). The mechanisms that elicit interstitial branching into targets are unknown. Direct video observations, however, have shown that at choice points in the corpus callosum where axons must make decisions about where to enter cortical targets, callosal growth cones display complex exploratory behaviors. In regions of other mammalian pathways in which individual axons branch interstitially into their targets, growth cones may exhibit similar decision-making behaviors.

In summary, time-lapse video microscopy of living callosal slices has for the first time permitted direct observation of growth cone behaviors along an entire pathway of the mammalian CNS. These observations have shown that growth cones in three different regions of the callosal pathway exhibit dramatically different behaviors that are likely to reflect differences in guidance cues in the tract, in the cortex, and in subtarget regions. The most complex callosal growth cone behaviors take place beneath cortical targets. We hypothesize that in these regions growth cone collapsing and resurging behaviors as well as exploratory transient branching represent a process of decision making by callosal growth cones. In future, it will be important to identify the cues that induce growth cone decision-making behaviors and determine how such behaviors lead to appropriate target innervation.

\section{References}

Baird DH, Hatten ME, Mason CA (1992) Cerebellar target neurons provide a stop signal for afferent neurite extension in vitro. J Neurosci 12:619-634.

Bentley D, Caudy M (1983) Navigational substrates for peripheral pioneer growth cones: limb-axis polarity cues, limb-segment boundaries, and guidepost neurons. Cold Spring Harbor Symp Quant Biol 48:573-585.

Rentley D, O'Connor TP (1991) Guidance and steering of peripheral pioneer growth cones in grasshopper embryos. In: The nerve growth cone (Letourneau PC, Kater SB, Macagno ER), pp 265-282. New York: Raven.

Bovolenta P, Dodd J (1990) Guidance of commissural growth cones at the floor plate in embryonic rat spinal cord. Development 109: 435-447.

Bovolenta P, Mason C (1987) Growth cone morphology varies with 
position in the developing mouse visual pathway from retina to first targets. J Neurosci 7:1447-1460.

Carvell GE, Simons DJ (1987) Thalamic and corticocortical connections of the second somatic sensory area of the mouse. J Comp Neurol 265:409-427.

Caudy M, Bentley D (1986) Pioneer growth cone morphologies reveal proximal increases in substrate affinity within leg segments of grasshopper embryos. J Neurosci 6:364-379.

Chien CB, Rosenthal DE, Harris WA, Holt CE (1993) Navigational errors made by growth cones without filopodia in the embryonic Xenopus brain. Neuron 11:237-251.

Cornel E, Holt C (1992) Precocious pathfinding: retinal axons can navigate in an axonless brain. Neuron 9:1001-1011.

Davies JA, Cook GMW (1991) Growth cone inhibition - an important mechanism in neural development? Bioessays 13:11-15.

Edwards MA, Yamamoto M, Caviness VS Jr (1990) Organization of radial glia and related cells in the developing murine CNS. An analysis based upon a new monoclonal antibody marker. Neuroscience 36: 121-144.

Gadisseux JF, Evrard P, Misson JP, Caviness VS Jr (1989) Dynamic structure of the radial glial fiber system of the developing murine cerebral wall. An immunocytochemical analysis. Dev Brain Res 50: 55-67.

Ghosh A, Shatz CJ (1992) Pathfinding and target selection by developing geniculocortical axons. J Neurosci 12:39-55.

Ghosh A, Antonini A, McConnell SK, Shatz CJ (1990) Requirement for subplate neurons in the formation of thalamocortical connections. Nature 347:179-181.

Godement P, Salaun J, Mason CA (1990) Retinal axon pathfinding in the optic chiasm: divergence of crossed and uncrossed fibers. Neuron 5:173-186.

Goldberg DJ, Burmeister DW (1986) Stages in axon formation: observations of growth of Aplysia axons in culture using video-enhanced contrast-differential interference contrast microscopy. J Cell Biol 103: 1921-1931.

Goldberg DJ, Burmeister DW (1989) Looking into growth cones. Trends Neurosci 12:503-506.

Goodman CS, Shatz CJ (1993) Developmental mechanisms that generate precise patterns of neuronal connectivity. Cell 72 /Neuron 10: 77-98.

Gotz M, Novak N, Bastmeyer M, Bolz J (1992) Membrane-bound molecules in rat cerebral cortex regulate thalamic innervation. Development 116:507-519.

Halloran MC, Kalil K (1991) Video microscopy of growth cones extending in the corpus callosum of a hamster cortical brain slice. Soc Neurosci Abstr 17:532.

Halloran MC, Kalil K (1992) Video microscopy of growth cones in decision regions of the corpus callosum in living cortical brain slices. Soc Neurosci Abstr 18:219.

Harris WA, Holt CE, Bonhoeffer F (1987) Retinal axons with and without their somata, growing to and arborizing in the tectum of Xenopus embryos: a time-lapse study of single fibres in vivo. Development 101:123-133.

Heffner C, Lumsden A, O'Leary DDM (1990) Target control of collateral extension and directional axon growth in the mammalian brain. Science 247:217-220.

Hogan D, Berman NEJ (1990) Growth cone morphology, axon trajectory and branching patterns in the neonatal rat corpus callosum. Dev Brain Res 53:283-287.

Honig MG, Hume RI (1986) DiI and DiO: versatile fluorescent dyes for neuronal labeling and pathway tracing. Trends Neurosci 9:333341.

Kaethner RJ, Stuermer CAO (1992) Dynamics of terminal arbor formation and target approach of retinotectal axons in living zebrafish embryos: a time-lapse study of single axons. J Neurosci 12:32573271.

Kalil K, Norris CR (1991) Pathfinding by growth cones in tracts and targets of the mammalian cerebral cortex. In: The nerve growth cone (Lctourncau PC, Katcr SB, Macagno ER), pp 425-446. New York: Raven.

Kapfhammer JP, Raper JA (1987) Collapse of growth cone structure on contact with specific neurites in culture. J Neurosci 7:201-212.

Kapfhammer JP, Grunewald BE, Raper JA (1986) The selective inhibition of growth cone extension by specific neurites in culture. $J$ Neurosci $6: 2527-2534$.
Koralek KA, Olavarria J, Killackey HP (1990) Areal and laminar organization of corticocortical projections in the rat somatosensory cortex. J Comp Neurol 299:133-150.

Lent R, Hedin-Pereira C, Menezes JRL, Jhaveri S (1990) Neurogenesis and development of callosal and intracortical connections in the hamster. Neuroscience 38:21-37.

Lu M, Kalil K (1992) Video microscopy of cell-cell interactions in dissociated cultures of developing mammalian cerebral cortex. Soc Neurosci Abstr 18:220.

Mason CA, Godement P (1991) Growth cone form reflects interactions in visual pathways and cerebellar targets. In: The nerve growth cone (Letourneau PC, Kater SB, Macagno ER), pp 405-423. New York: Raven.

Miller MW, Vogt BA (1984) Heterotopic and homotopic callosal connections in rat visual cortex. Brain Res 297:75-89.

Misson JP, Edwards MA, Yamamoto M, Caviness VS Jr (1988) Identification of radial glial cells within the developing murine central nervous system: studies based upon a new immunohistochemical marker. Dev Brain Res 44:95-108.

Myers PZ, Bastiani MJ (1993) Growth cone dynamics during the migration of an identified commissural growth cone. J Neurosci 13: $127-143$.

Myers PZ, Eisen JS, Westerfield M (1986) Development and axonal outgrowth of identified motoneurons in the zebrafish. J Neurosci $6: 2278-2289$

Nordlander RH (1987) Axonal growth cones in the developing amphibian spinal cord. J Comp Neurol 263:485-496.

Nordlander RH, Gazzerro JW, Cook H (1991) Growth cones and axon trajectories of a sensory pathway in the amphibian spinal cord. J Comp Neurol 307:539-548.

Norris CR, Kalil K (1990) Morphology and cellular interactions of growth cones in the developing corpus callosum. J Comp Neurol 293: $268-281$.

Norris CR, Kalil K (1991) Guidance of callosal axons by radial glia in the developing cerebral cortex. J Neurosci 11:3481-3492.

Norris CR, Kalil K (1992) Development of callosal connections in the sensorimotor cortex of the hamster. J Comp Neurol 326:121132.

O'Connor TP, Duerr JS, Bentley D (1990) Pioneer growth cone steering decisions mediated by single filopodial contacts in situ. J Neurosci 10:3935-3946.

Olavarria J, Van Sluyters RC (1986) Axons from restricted regions of the cortex pass through restricted portions of the corpus callosum in adult and neonatal rats. Dev Brain Res 25:309-313.

O'Leary DDM, Terashima T (1988) Cortical axons branch to multiple subcortical targets by interstitial axon budding: implications for target recognition and "waiting periods." Neuron 1:901-910.

O'Rourke NA, Fraser SE (1990) Dynamic changes in optic fiber terminal arbors lead to retinotopic map formation: an in vivo confocal microscopic study. Neuron 5:159-171.

O'Rourke NA, Dailey ME, Smith SJ, McConnell SK (1992) Diverse migratory pathways in the developing cerebral cortex. Science 258 : 299-302.

Patterson PH (1988) On the importance of being inhibited, or saying no to growth cones. Neuron 1:263-267.

Qian J, Bull MS, Levitt P (1992) Target-derived astroglia regulate axonal outgrowth in a region-specific manner. Dev Biol 149:278-294.

Rakic P (1971) Guidance of neurons migrating to the fetal monkey neocortex. Brain Res 33:471-476.

Rakic P (1972) Mode of cell migration to the superficial layers of fetal monkey neocortex. J Comp Neurol 145:61-84.

Rakic P (1988) Specification of cerebral cortical areas. Science 241: 170-176.

Raper JA, Bastiani M, Goodman CS (1983a) Pathfinding by neuronal growth cones in grasshopper embryos. I. Divergent choices made by the growth cones of sibling neurons. J Neurosci 3:20-30.

Raper JA, Bastiani MJ, Goodman CS (1983b) Guidance of neuronal growth cones: selective fasciculation in the grasshopper embryo. Cold Spring Harbor Symp Quant Biol 48:587-598.

Rhoades RW, Dellacroce DD (1980) Visual callosal connections in the golden hamster. Brain Res 190:248-254.

Sabry JH, O'Connor TP, Evans L, Toroian-Raymond A, Kirschner M, Bentley D (1991) Microtubule behavior during guidance of pioneer neuron growth cones in situ. J Cell Biol 115:381-395.

Sretavan DW, Reichardt LF (1993) Time-lapse video analysis of ret- 
inal ganglion cell axon pathfinding at the mammalian optic chiasm: growth cone guidance using intrinsic chiasm cues. Neuron 10:761777.

Tosney KW, Landmesser LT (1985) Growth cone morphology and trajectory in the lumbosacral region of the chick embryo. $J$ Neurosci 5:2345-2358.

Waltcr J, Allsopp TE, Bonhoeffer F (1990) A common denominator of growth cone guidance and collapse? Trends Neurosci 13:447-452.
Wise SP, Jones EG (1976) The organization and postnatal development of the commissural projection of the rat somatic sensory cortex. J Comp Neurol 168:313-344.

Yorke CH, Caviness VS Jr (1975) Interhemispheric neocortical connections of the corpus callosum in the normal mouse: a study based on anterograde and retrograde methods. J Comp Neurol 164:233246. 